\title{
International Comparison of the Levels and Potential Correlates of Objectively Measured Sedentary Time and Physical Activity among Three-to-Four-Year-Old Children
}

\author{
Kaiseree I Dias ${ }^{1, *}{ }^{\circ}$, James White ${ }^{2}$, Russell Jago $\left.{ }^{3}{ }^{(}\right)$, Greet Cardon ${ }^{4}\left(\mathbb{D}\right.$, Rachel Davey ${ }^{5}$, \\ Kathleen F Janz ${ }^{6}$, Russell R Pate ${ }^{7}$, Jardena J Puder ${ }^{8}$, John J Reilly ${ }^{9}{ }^{(D}$ and Ruth Kipping ${ }^{1}$ on \\ behalf of International Children's Accelerometry Database (ICAD) Collaborators ${ }^{\dagger}$
}

1 Population Health Sciences, Bristol Medical School, University of Bristol, Oakfield House, Oakfield Grove, Clifton, Bristol BS8 2BN, UK; ruth.kipping@bristol.ac.uk

2 Centre for Trials Research, School of Medicine, Cardiff University, 4th Floor Neuadd Meirionnydd, Heath Park, Cardiff CF14 4YS, UK; whitej11@cardiff.ac.uk

3 Centre for Exercise, Nutrition and Health Sciences, School for Policy Studies, University of Bristol, 8 Priory Road, Bristol BS8 1TZ, UK; russ.jago@bristol.ac.uk

4 Department of Movement and Sports Sciences, Ghent University, 9000 Ghent, Belgium; Greet.Cardon@UGent.be

5 Centre for Research \& Action in Public Health, Health Research Institute, University of Canberra, Canberra, ACT 2601, Australia; rachel.davey@canberra.edu.au

6 Department of Health and Human Physiology, University of Iowa, Iowa City, IA 52242, USA; kathleen-janz@uiowa.edu

7 Department of Exercise Science, University of South Carolina, Columbia, SC 29208, USA; RPATE@mailbox.sc.edu

8 Obstetric service, Department Woman-Mother-Child, Lausanne University Hospital, 1005 Lausanne, Switzerland; jardena.puder@chuv.ch

9 School of Psychological Sciences and Health, University of Strathclyde, Glasgow G1 1QE, UK; john.j.reilly@strath.ac.uk

* Correspondence: kaiseree.dias@bristol.ac.uk; Tel.: +44-117-331-0076

† Andrew J Atkin (a.atkin@uea.ac.uk); Ulf Ekelund (ulf.ekelund@nih.no); Dale W Esliger (d.esliger@lboro.ac.uk); Bjørge H Hansen (bjorge.h.hansen@uia.no); Lauren B Sherar (l.b.sherar@lboro.ac.uk); Esther M F van Sluijs (esther.vansluijs@mrc-epid.cam.ac.uk)

Received: 15 April 2019; Accepted: 26 May 2019; Published: 31 May 2019

\begin{abstract}
Physical activity (PA) patterns track from childhood through to adulthood. The study aimed to determine the levels and correlates of sedentary time (ST), total PA (TPA), and moderate-to-vigorous PA (MVPA) in preschool-aged children. We conducted cross-sectional analyses of 1052 children aged three-to-four-years-old from six studies included in the International Children's Accelerometry Database. Multilevel linear regression models adjusting for age, gender, season, minutes of wear time, and study clustering effects were used to estimate associations between age, gender, country, season, ethnicity, parental education, day of the week, time of sunrise, time of sunset, and hours of daylight and the daily minutes spent in ST, TPA, and MVPA. Across the UK, Switzerland, Belgium, and the USA, children in our analysis sample spent $490 \mathrm{~min}$ in ST per day and $30.0 \%$ and $21.2 \%$ of children did not engage in recommended daily TPA $(\geq 180 \mathrm{~min})$ and MVPA ( $\geq 60 \mathrm{~min})$ guidelines. There was evidence for an association between all 10 potential correlates analyzed and at least one of the outcome variables; average daily minutes spent in ST, TPA and/or MVPA. These correlates can inform the design of public health interventions internationally to decrease ST and increase PA in preschoolers.
\end{abstract}


Keywords: child; preschool; accelerometry; physical activity; sedentary behavior; cross-sectional studies; ICAD

\section{Introduction}

Physical activity (PA) patterns track from childhood through to adulthood [1], making preschool-aged children an important population to target for physical activity interventions. Being physically active during the early years is associated with improved adiposity, cardiometabolic health indicators, motor skill development, bone and skeletal health, cognitive development, and psychosocial health [2]. Current Canadian [3] and Australian [4] guidelines advise that children aged two-to-five-years-old should not be sedentary for periods of over $60 \mathrm{~min}$ at a time. The Canadian, Australian, USA [5], and UK [6] guidelines also specify that children under the age of five, who can walk unaided, should be physically active for at least $180 \mathrm{~min}$ per day and should spend at least $60 \mathrm{~min}$ of this time in moderate-to-vigorous PA (MVPA) [3,4]. Only a few studies have looked at the proportion of preschool-aged children meeting these PA guidelines using objective measures of PA. Two studies from the UK $[7,8]$ found that $100 \%$ of children aged three-to-four-years met the recommended $\geq 180 \mathrm{~min}$ a day of total PA (TPA) whereas a Belgian [9], Australian [10], and Canadian [11] study found that $11.0 \%, 5.1 \%$, and $83.8 \%$ of preschool-aged children met these guidelines, respectively. Furthermore, the Canadian study found that $13.7 \%$ of five-year-olds spent $\geq 60 \mathrm{~min}$ in MVPA per day [11]. It is, however, not possible to establish whether children in the UK are more physically active than children in Canada and Australia due to differences in definitions of accelerometer wear time applied across these studies $[12,13]$. This emphasizes the importance of applying standardized data processing methods to ensure comparisons across countries are valid.

A key stage in the development of behavior change interventions is identifying variables which could either be potential targets to change behavior (mediators) or variables that could affect the outcome of the behavior change program (moderators). Therefore, identifying the key correlates of preschoolers' sedentary time (ST) and PA is important for designing effective behavior change programs [14]. Narrative reviews have assessed the correlates of ST $[15,16]$ and PA $[16,17]$ in preschool-aged children. Across the reviews, there was inconsistent support for associations between ST and PA with correlates. For example, one review concluded boys were more active than girls [17], whereas the other did not [16]. Conflicting findings were also observed for day of the week, where one review found no association [17] and the other found a positive association [16] with physical activity. Both found no association between age, ethnicity, season, or parent education with physical activity $[16,17]$. All three reviews were limited in that they included studies which used self-report measures of ST and PA, which may not accurately detect associations. Since these reviews were published, there have been a few additional studies which have assessed the correlates of ST and/or PA in preschool-aged children using objectively measured accelerometry data [18-25]. The findings across these studies are similarly inconsistent, and there is the issue of comparability as they have processed accelerometry data using different methods of processing and analyzing data [18-25]. In addition, none of the studies have made cross-national comparisons of the proportion of children meeting guideline levels of ST, TPA, and MVPA and using a standardized method of processing accelerometry data. Accordingly, we aim to determine the levels and correlates of ST, TPA, and MVPA in children aged three-to-four-years-old using data from four countries, applying a consistent approach to data processing.

\section{Methods}

\subsection{Study Design}

Cross-sectional analyses were carried out on data obtained from the International Children's Accelerometry Database (ICAD), which has been described in detail elsewhere [26]. In brief, the 
ICAD is a pooled database of raw Actigraph accelerometer (Actigraph LLC, Pensacola, FL, USA) data files and accompanying demographic, anthropometric, and health data collected from children (2-18-years) between 1997 and 2009. Data were pooled from 20 studies conducted in 11 countries and included cross-sectional, longitudinal, intervention, and closed cohort studies. Data were reduced using standardized techniques to allow for comparison of physical activity outcome variables across studies (see below). Formal data sharing agreements were established between all study authors and ICAD. All studies consulted their individual research boards to confirm that appropriate ethical approval had been attained for contributing data.

\subsection{Participants}

For this paper, the analytical sample consists of children aged three-to-four-years-old who had at least three days (week and/or weekend days) of valid accelerometry data [27]. To maintain the independence of the observations, follow-up waves of data were excluded from the analyses $(n=17)$. Participants aged two-years-old $(n=17)$ and participants from Australia $(n=7)$ were excluded due to the very small sample sizes for these groups. Data for the analysis sample were extracted from six studies: Ballabeina Study [28]—Switzerland; Belgium Pre-School Study [29-31]—Belgium; Children's Health and Activity Monitoring Programme (CHAMPS) UK [32,33]—UK; CHAMPS U.S. [34]—USA.; Iowa Bone Development Study (IBDS) [35,36]—USA.; and Movement and Activity Glasgow Intervention in Children (MAGIC) [37]—UK.

\subsection{Physical Activity Measurement}

Physical activity was measured using waist-worn, uniaxial Actigraph accelerometers (models 7164, 71256, and GT1M). Raw data files were processed using KineSoft version 3.3.20 (KineSoft, Sakatchewan, SK, Canada). Non-wear time was defined as periods of $60 \mathrm{~min}$ of consecutive zeros allowing for two minutes of non-zero interruptions [38]. A day was considered valid if there was at least $480 \mathrm{~min}$ of accelerometry data [27]. The analysis of physical activity data was restricted to 06:00 and 21:59 to exclude the times when the children would be asleep [39]. When looking at physical activity patterns across the day, hours with less than two minutes of wear time were removed from the analyses [38]. Physical activity thresholds available in the ICAD were those specified by Puyau et al. [40] and Pate et al. [41]: sedentary ( $<800 \mathrm{cpm})$ [40], TPA ( $\geq 800 \mathrm{cpm}$ ) [40] and MVPA ( $\geq 1680 \mathrm{cpm})$ [41]. Mean hourly, daily, weekday, and weekend minutes spent in ST, TPA, and MVPA across the whole week were the outcome variables.

\subsection{Variables}

The following 10 potential correlates were examined: age, gender, country, season, ethnicity, parental education, day of the week (weekday vs weekend), time of sunrise, time of sunset, and hours of daylight. These variables were explored based on a combination of what was available and what had been identified as potential correlates by previous studies [15-17]. Ethnicity data were available from three studies in our analysis sample and categorized as white or other (non-white). Parental education was available from four studies and was dichotomized into 'up to and including completion of compulsory education including vocational training' and 'any post-compulsory education including vocational training' as a measure of socioeconomic status. The season, time of sunrise, time of sunset, and hours of daylight variables were derived from the date that the accelerometer started collecting data and the city, or nearest city, where the study took place using the website www.timeanddate.com. The countries in our sample were all in the Northern Hemisphere and therefore, had the same seasons (spring: March-May; summer: June-August; autumn: September-November; winter: December-February). The time of sunrise variable, time of sunset, and hours of daylight variables were categorized into before and after 07:00; before and after 19:00; and less than or more than $12 \mathrm{~h}$, respectively. 


\subsection{Statistical Analyses}

Participant characteristics were summarized using frequencies and percentages for categorical data. The percentage of children meeting the recommended daily guidelines of $\geq 180$ min of TPA [3-6] and $\geq 60$ min MVPA [3,4] were compared across categories of each correlate using chi-squared tests. Mean minutes spent in ST, TPA, and MVPA were plotted for every hour between 06:00 and 21:59. Adjusted multilevel linear regression models were used to determine the association between ST, TPA, and MVPA for each potential correlate. Models were adjusted for age, gender, season, minutes of wear time, and study clustering effects. Linear regression analyses were undertaken assuming a linear relationship, multivariate normality, homoscedasticity, and little multicollinearity which were tested via inspection of scatter plots of the outcomes vs. the independent variable; histograms of the outcome variables; scatter plots of the residual errors vs. the linear predictor; and variance inflation factors of the variables included in the models, respectively. Results from the assumption tests clarified that these assumptions had been met (data not shown). Intraclass correlation coefficients (ICCs) and R-squared values $\left(\mathrm{R}^{2}\right)$, as proposed by Snijders and Bosker [42], were calculated for each of the models. Some studies $[43,44]$ suggest that four valid days of accelerometry data are needed to reliably measure ST/PA levels to achieve an ICC of $\geq 0.7$ when using the accelerometry thresholds specified in our analyses $[40,41]$. Sensitivity analyses were, therefore, carried out on a sample where participants had at least four days of valid accelerometry data. All analyses were carried out in Stata v15 (StataCorp, College Station, TX, USA).

\section{Results}

\subsection{Participant Characteristics}

The 1052 participants in the analysis sample (Table 1) contributed an average of 4.82 days of data comprising 3.79 weekdays and 1.03 weekend days. The average daily wear time between 6:00 to 21:59 was $697.27 \mathrm{~min}$ (see Supplementary Table S1). Data were collected between September 1998 and June 2009. Out of the six studies which contributed data, most participants were from the UK-based MAGIC study $(36.8 \%)$.

Table 1. Sociodemographic characteristics of children.

\begin{tabular}{cc}
\hline Characteristic & $N(\%)$ \\
\hline Overall & $1052(100.00)$ \\
\hline Age & $343(32.60)$ \\
\hline 3 & $709(67.40)$ \\
\hline Gender & \\
\hline Male & $528(50.19)$ \\
Female & $524(49.81)$ \\
\hline Country & \\
\hline UK & $426(40.49)$ \\
Switzerland & $142(13.50)$ \\
Belgium & $104(9.89)$ \\
USA & $380(36.12)$ \\
\hline Season & $136(12.93)$ \\
\hline Winter & $110(10.46)$ \\
Spring & $117(11.12)$ \\
Summer & $689(65.49)$ \\
\hline Autumn &
\end{tabular}


Table 1. Cont.

\begin{tabular}{|c|c|}
\hline Characteristic & $N(\%)$ \\
\hline \multicolumn{2}{|l|}{ Ethnicity } \\
\hline White & $200(19.01)$ \\
\hline Other & $219(20.82)$ \\
\hline Missing/Not available & $633(60.17)$ \\
\hline \multicolumn{2}{|l|}{ Parental Education } \\
\hline Up to and including completion of compulsory vocational training & $86(8.17)$ \\
\hline Any post-compulsory education including vocational training & $300(28.52)$ \\
\hline Missing/Not available & $666(63.31)$ \\
\hline \multicolumn{2}{|l|}{ Day of the Week } \\
\hline Weekday & $1052(100.00)$ \\
\hline Weekend & $626(59.51)$ \\
\hline \multicolumn{2}{|l|}{ Time of Sunrise } \\
\hline Before 07:00 & $433(41.16)$ \\
\hline After 07:00 & $619(58.84)$ \\
\hline \multicolumn{2}{|l|}{ Time of Sunset } \\
\hline Before 19:00 & $548(52.09)$ \\
\hline After 19:00 & $504(47.91)$ \\
\hline \multicolumn{2}{|l|}{ Hours of Daylight } \\
\hline Less than $12 \mathrm{~h}$ & $589(55.99)$ \\
\hline More than $12 \mathrm{~h}$ & $463(44.01)$ \\
\hline \multicolumn{2}{|l|}{ Study } \\
\hline Ballabeina & $142(13.50)$ \\
\hline Belgium Pre-School & $104(9.89)$ \\
\hline CHAMPS U.S. & $361(34.32)$ \\
\hline MAGIC & $387(36.79)$ \\
\hline CHAMPS UK & $39(3.71)$ \\
\hline IBDS & $19(1.81)$ \\
\hline
\end{tabular}

3.2. Percentage of Children Meeting Canadian, Australian, USA and UK Guidelines for Sedentary Time, Total Physical Activity, and Moderate-to-Vigorous Physical Activity

Participants spent an average of $490.18 \mathrm{~min}$ per day in ST (see Supplementary Table S1). Table 2 shows that $70.0 \%$ of participants met recommended daily guidelines of $\geq 180 \mathrm{~min}$ of TPA and $78.8 \%$ of participants met daily guidelines of $\geq 60 \mathrm{~min}$ of MVPA, based on TPA ( $\geq 800 \mathrm{cpm}$ ) [40] and MVPA ( $\geq 1680 \mathrm{cpm}$ ) [41] thresholds specified by Puyau et al. and Pate et al. A greater percentage of four-year -olds than three-year-olds and boys than girls met the recommended guidelines for TPA and MVPA. Our findings suggest that the percentage of children reaching TPA and MVPA guidelines varied between the different countries. The lowest percentage of children achieving guideline MVPA levels was observed in Belgium (50.0\%), and the highest percentage was observed in the USA $(88.7 \%)$. The percentage of children reaching the recommended TPA and MVPA levels increased from winter through to summer before it decreased in autumn and was greater on weekdays compared to weekends. A greater percentage of non-white children met the MVPA guidelines compared to white children $(92.7 \%$ vs. $\left.78.0 \%, X^{2}=18.40, p<0.001\right)$. When the hours of daylight were more than $12 \mathrm{~h}$, a greater percentage of children met TPA $\left(76.2 \%\right.$ vs. $\left.65.0 \%, X^{2}=15.52, p<0.001\right)$ and MVPA $\left(85.1 \%\right.$ vs. $73.9 \%, X^{2}=19.62, p$ $<0.001$ ) guidelines compared to when days were less than $12 \mathrm{~h}$ long. A greater percentage of children met TPA and MVPA guidelines when the time of sunrise was before 07:00 and the time of sunset was after 19:00 compared to being after 07:00 and before 19:00. No differences were observed for parental education. 
Table 2. Frequency and percentage of children meeting internationally recognized guidelines of $\geq 180$ min of total physical activity per day and $\geq 60 \mathrm{~min}$ of moderate-to-vigorous physical activity per day by the different correlates.

\begin{tabular}{|c|c|c|c|c|c|c|c|}
\hline Correlate & $\mathbf{N}$ & $\begin{array}{c}\geq 180 \mathrm{~min} \\
\text { of TPA }\end{array}$ & $X^{2}$ & $p$ & $\begin{array}{c}\geq 60 \mathrm{~min} \\
\text { of MVPA }\end{array}$ & $X^{2}$ & $p$ \\
\hline Overall & 1052 & $736(69.96)$ & N/A & N/A & $829(78.80)$ & $\mathrm{N} / \mathrm{A}$ & N/A \\
\hline \multicolumn{8}{|l|}{ Age } \\
\hline 3 & 343 & $223(65.01)$ & & & $257(74.93)$ & & \\
\hline 4 & 709 & $513(72.36)$ & 5.93 & 0.015 & $572(80.68)$ & 4.58 & 0.032 \\
\hline \multicolumn{8}{|l|}{ Gender } \\
\hline Male & 528 & $406(76.89)$ & & & $451(85.42)$ & & \\
\hline Female & 524 & $330(62.98)$ & 24.24 & $<0.001$ & $378(72.14)$ & 27.76 & $<0.001$ \\
\hline \multicolumn{8}{|l|}{ Country } \\
\hline UK & 426 & 297 (69.72) & & & $332(77.93)$ & & \\
\hline Switzerland & 142 & 99 (69.72) & & & $108(76.06)$ & & \\
\hline Belgium & 104 & $46(44.23)$ & & & $52(50.00)$ & & \\
\hline USA & 380 & $294(77.37)$ & 42.70 & $<0.001$ & $337(88.68)$ & 74.70 & $<0.001$ \\
\hline \multicolumn{8}{|l|}{ Season } \\
\hline Winter & 136 & $82(60.29)$ & & & $93(68.38)$ & & \\
\hline Spring & 110 & 79 (71.82) & & & 85 (77.27) & & \\
\hline Summer & 117 & $90(76.92)$ & & & $106(90.60)$ & & \\
\hline Autumn & 689 & $485(70.39)$ & 8.99 & 0.029 & $545(79.10)$ & 18.78 & $<0.001$ \\
\hline \multicolumn{8}{|l|}{ Ethnicity } \\
\hline White & 200 & $143(71.50)$ & & & $156(78.00)$ & & \\
\hline Other & 219 & $171(78.08)$ & 2.41 & 0.120 & $203(92.69)$ & 18.40 & $<0.001$ \\
\hline \multicolumn{8}{|l|}{ Parental Education } \\
\hline $\begin{array}{l}\text { Up to and including } \\
\text { completion of compulsory } \\
\text { vocational training }\end{array}$ & 86 & $73(84.88)$ & & & 81 (94.19) & & \\
\hline $\begin{array}{c}\text { Any post-compulsory } \\
\text { education including } \\
\text { vocational training }\end{array}$ & 300 & $226(75.33)$ & 3.49 & 0.062 & $260(86.67)$ & 3.67 & 0.055 \\
\hline \multicolumn{8}{|l|}{ Weekday vs. Weekend } \\
\hline Weekday & 1052 & $720(68.44)$ & & & $813(77.28)$ & & \\
\hline Weekend & 626 & $386(61.66)$ & 8.03 & 0.005 & $423(67.57)$ & 19.07 & $<0.001$ \\
\hline \multicolumn{8}{|l|}{ Time of Sunrise } \\
\hline Before 07:00 & 433 & $344(79.45)$ & & & $382(88.22)$ & & \\
\hline After 07:00 & 619 & $392(63.33)$ & 31.49 & $<0.001$ & $447(72.21)$ & 39.09 & $<0.001$ \\
\hline \multicolumn{8}{|l|}{ Time of Sunset } \\
\hline Before 19:00 & 548 & $350(63.87)$ & & & $399(72.81)$ & & \\
\hline After 19:00 & 504 & $386(76.59)$ & 20.21 & $<0.001$ & $430(85.32)$ & 24.59 & $<0.001$ \\
\hline \multicolumn{8}{|l|}{ Hours of daylight } \\
\hline Less than $12 \mathrm{~h}$ & 589 & $383(65.03)$ & & & $435(73.85)$ & & \\
\hline More than $12 \mathrm{~h}$ & 463 & $353(76.24)$ & 15.52 & $<0.001$ & $394(85.10)$ & 19.62 & $<0.001$ \\
\hline
\end{tabular}

\subsection{Patterns of Sedentary Time and Physical Activity across the Day}

Figure 1 shows that ST levels increase until around 09:00 and then decrease throughout the day, whereas TPA and MVPA levels increase throughout the day with variations in PA by country, day of the week and hours of daylight between 11:00 and 15:00. Figure 1A suggests that children from the USA showed a greater dip in TPA and MVPA levels between 11:00 and 15:00 than that observed around 12:00 in the UK and in Switzerland. Minutes spent in ST appear to have been higher on weekdays compared to weekends (Figure 1B) until 14:00 and 15:00 when minutes spent in ST became similar. On weekdays, the minutes spent in TPA and MVPA rose until 10:00 to 11:00 before dipping, whereas, 
on weekends, the minutes spent in TPA and MVPA increased gradually throughout the day before reaching a peak at the same time as weekdays at around 16:00. Between the hours 09:00 and 18:00, the minutes spent in ST were higher when the hours of daylight were less than $12 \mathrm{~h}$ compared to being more than $12 \mathrm{~h}$ (Figure 1C). The minutes spent in TPA and MVPA were noticeably higher when the hours of daylight were more than $12 \mathrm{~h}$ long, apart from the period before 09:00 and at the dipped levels observed between 12:00 and 15:00 where levels were similar to those observed on days which are less than $12 \mathrm{~h}$ long.
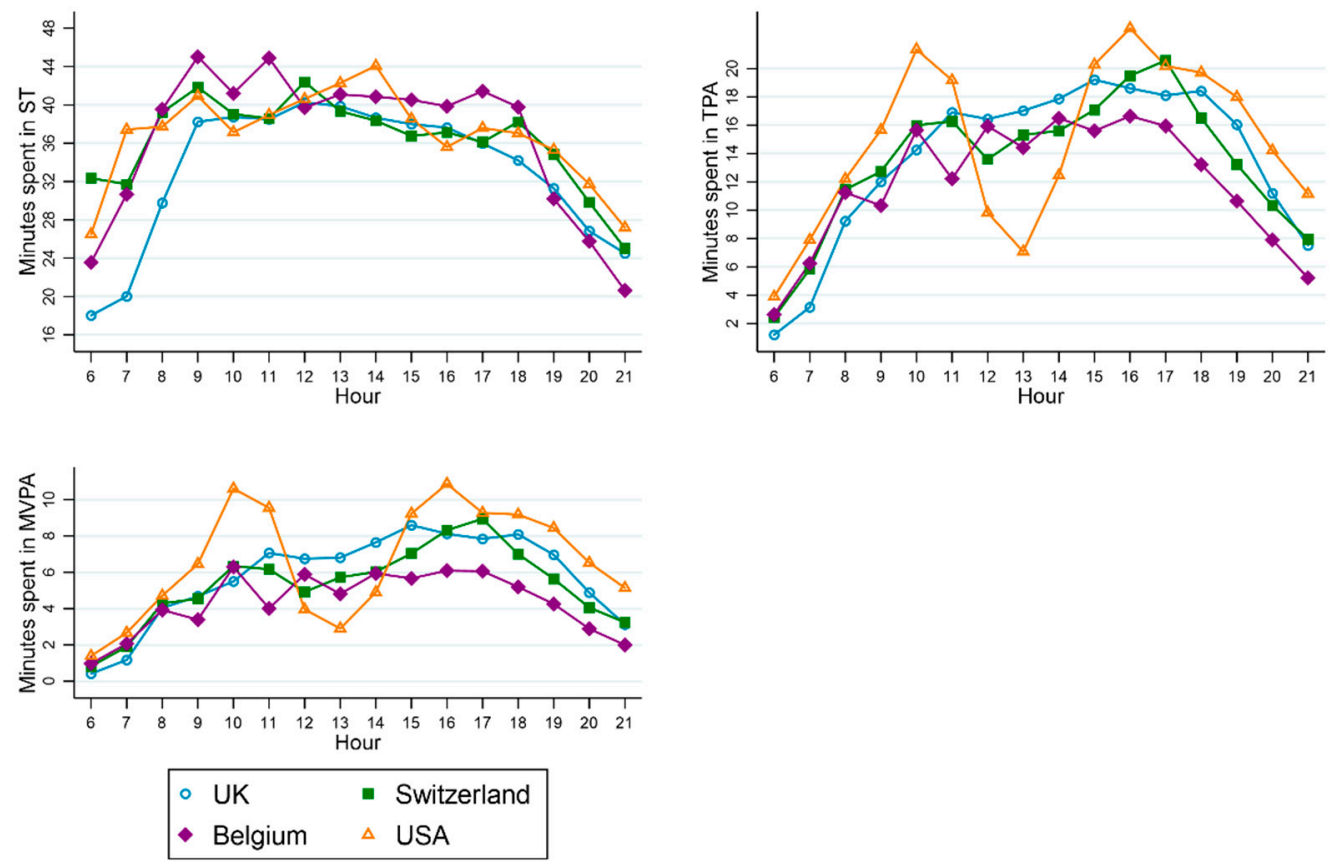

(A)
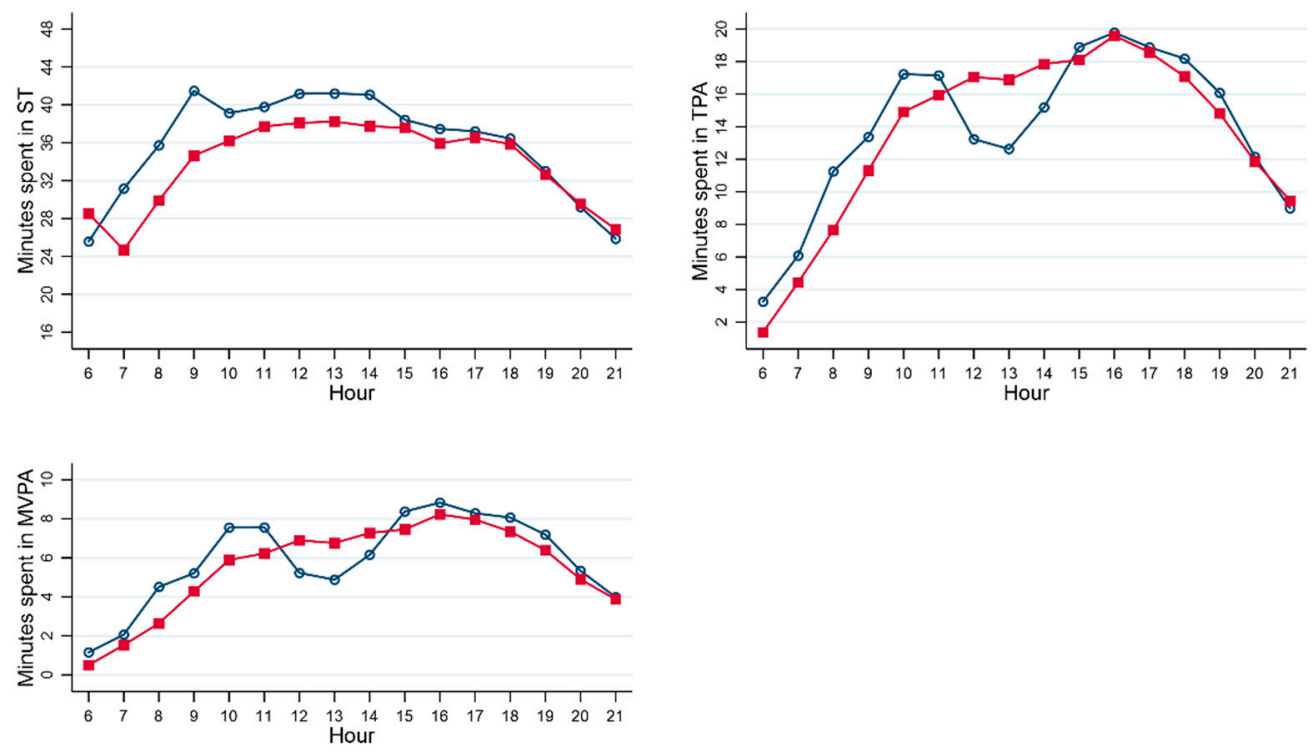

- Weekday

- Weekend

(B)

Figure 1. Cont. 

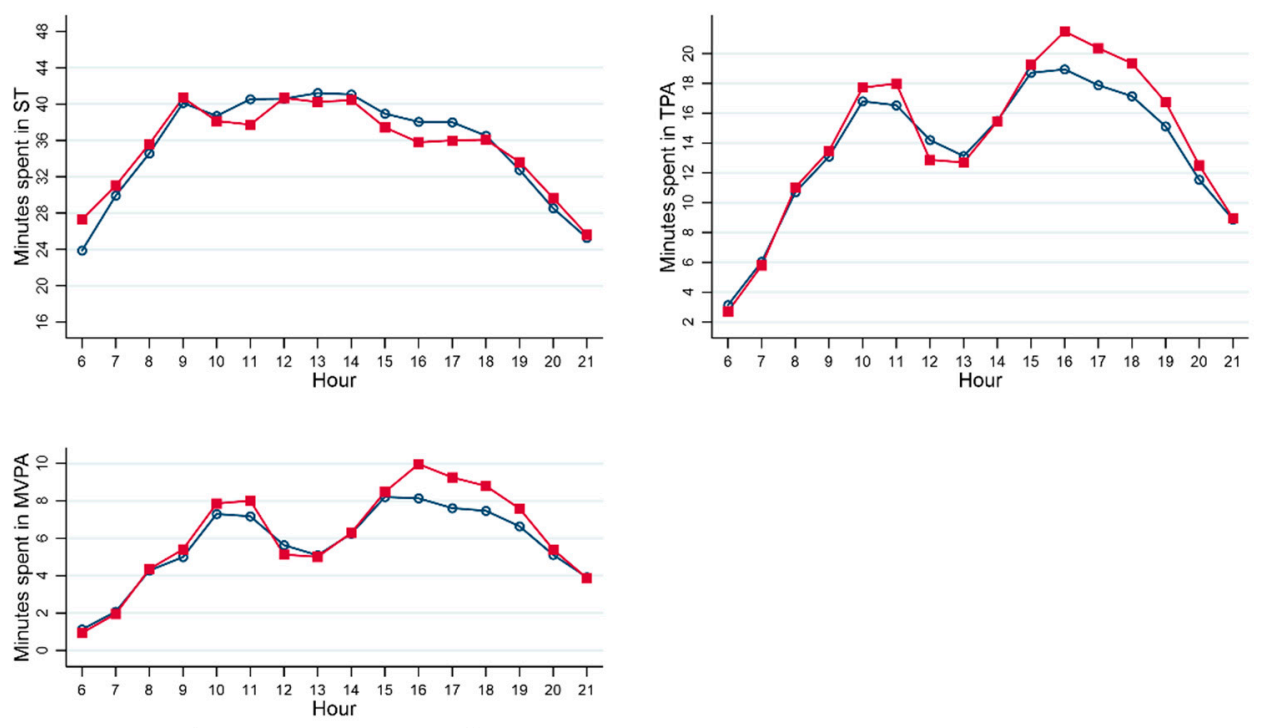

- Less than 12 hours

- More than 12 hours

(C)

Figure 1. Mean minutes spent in sedentary time, total physical activity, and moderate-to-vigorous physical activity according to the hours of the day by (A) country, (B) day of the week (weekday vs. weekend), and (C) hours of daylight. Figure 1A shows the by country differences in minutes spent in ST, TPA, and MVPA by hour. (Figure 1B shows the differences in minutes spent in ST, TPA, and MVPA by hour on weekdays compared to weekends. Figure 1C shows the differences in minutes spent in ST, TPA, and MVPA by hour when the hours of daylight are less than $12 \mathrm{~h}$ long compared to being more than $12 \mathrm{~h}$ long.)

\subsection{Correlates of Sedentary Time and Physical Activity in Preschool-Aged Children}

Table 3 shows the adjusted associations between the potential correlates and average daily minutes spent in ST, TPA, and MVPA after adjusting for age, gender, season, minutes of wear time, and study level clustering. Minutes spent in ST were higher, while minutes spent in TPA were lower, in girls, winter, and children whose parental education levels were higher compared to boys, spring, and lower parental education levels, respectively. Children spent more minutes in ST on weekdays compared to weekends and in MVPA summer compared to winter. There was evidence that four-year-olds, boys, and non-white children spent more time in MVPA compared to three-year-olds, girls, and white children, respectively. Minutes spent in ST were lower and the time spent in TPA/MVPA was higher when the hours of daylight were greater, i.e., when the time of sunrise was before 07:00, time of sunset was after 19:00 and when the hours of daylight were longer than $12 \mathrm{~h}$ long. UK-based children spent more time in TPA and fewer minutes in ST compared to children from Switzerland, Belgium, and the USA but only spent more time in MVPA compared to Switzerland and Belgium. The unadjusted analysis findings are available in Supplementary Table S2. 
Table 3. Multi-level adjusted associations between potential correlates and average daily minutes spent in sedentary time, total physical activity, and moderate-to-vigorous physical activity in children aged 3-to-4-years-old.

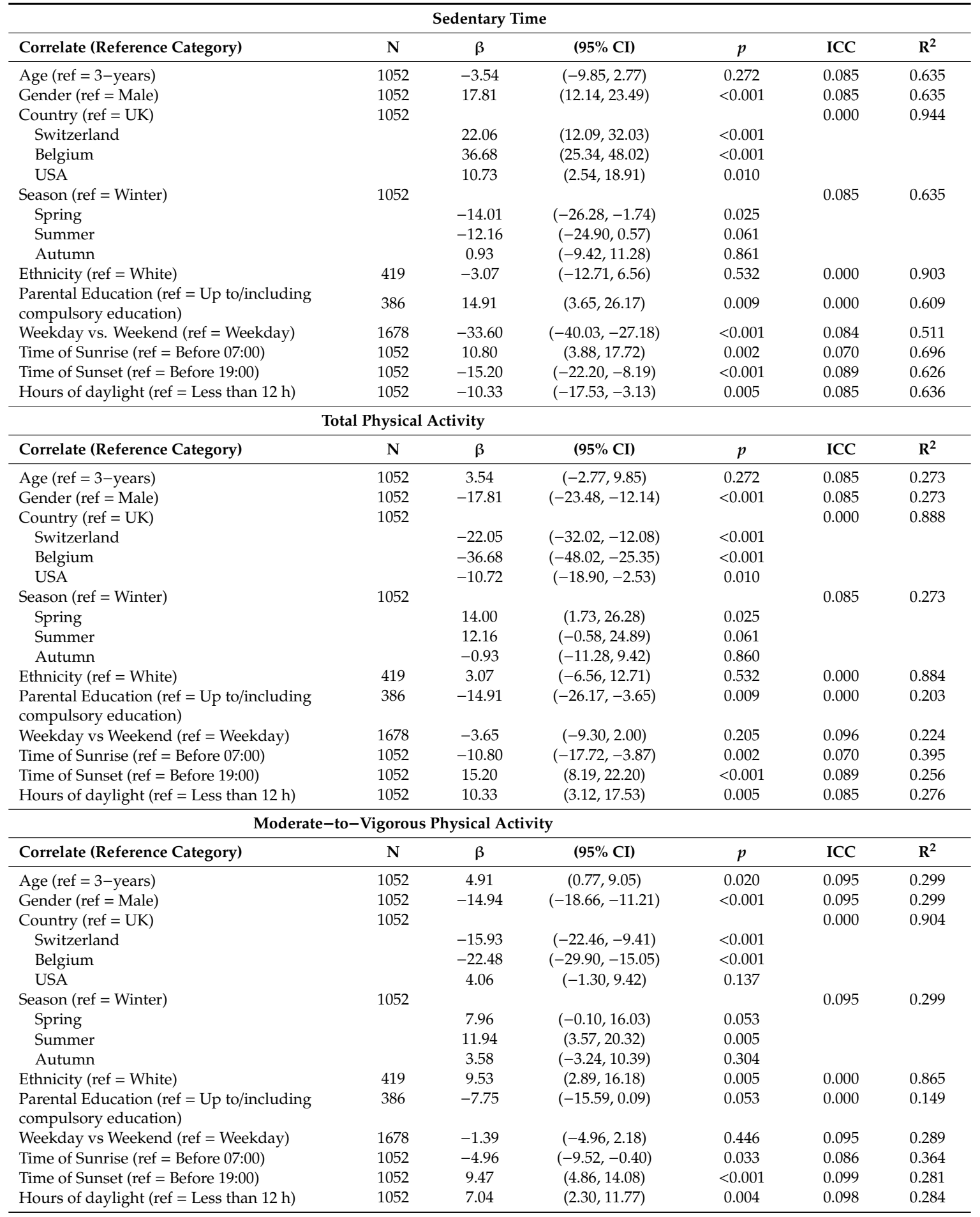

Note: CI: Confidence Interval, ICC: Intraclass Correlation Coefficient. All models are adjusted for age, gender, season, minutes of wear time, and study clustering effects.

\section{Discussion}

This study aimed to determine the levels and correlates of objectively measured ST, TPA, and MVPA in preschool-aged children using pooled data from the ICAD, which has been processed and analyzed using standardized methods. Across four high-income countries, three-to-four-year-olds 
were sedentary for an average of over $8 \mathrm{~h}$ per day. Thirty percent of the preschool-aged children were not engaging in the recommended $\geq 180 \mathrm{~min}$ of TPA, and $21.2 \%$ were not getting $\geq 60 \mathrm{~min}$ of MVPA per day. Data by each hour suggest that the minutes spent in ST decreased throughout the day, and the dips in TPA and MVPA levels generally observed between 11:00 and 15:00 were more prominent on weekdays compared to weekends, and in the USA compared to the other three countries. There was evidence for an association between all 10 potential correlates analyzed and at least one of the outcome variables; average daily minutes spent in ST, TPA, and/or MVPA.

Overall, $70.0 \%$ of our sample achieved $\geq 180 \mathrm{~min}$ of TPA, which differs to findings from the UK [7,8], Belgian [9], Australian [10], and Canadian [11] studies which found that $100 \%, 11.0 \%, 5.1 \%$, and $83.8 \%$ of preschool-aged children achieved recommended guidelines, respectively. Compared to the TPA threshold used in our study $(\geq 800 \mathrm{cpm}$ ) [40], the two UK studies and Canadian study

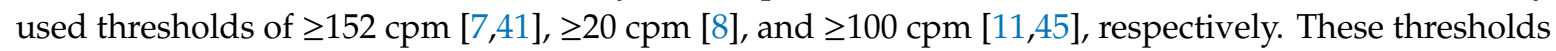
are lower than the ones used in this study, and therefore, a greater percentage of their participants could have achieved the PA guidelines. Similarly, the Belgian [9] and Australian [10] studies used thresholds described by Reilly et al. ( $\geq 1100 \mathrm{cpm}$ ) [46] and Sirard et al. (3-years: $\geq 1208 \mathrm{cpm}$; 4-years: $\geq 1456$ cpm; 5-years: $\geq 1596$ cpm) [47] which are higher than our study and may explain why such a small percentage of their samples achieved daily TPA guidelines compared to our sample. The Canadian study [11] found that $13.7 \%$ of five-year-olds spent $\geq 60 \mathrm{~min}$ in MVPA per day, whereas $78.8 \%$ of our sample achieved these recommendations. In comparing the different thresholds used in the studies, one might expect the percentage of our participants who achieved the recommended MVPA guidelines to be lower than the Canadian study, as they used a lower MVPA threshold, but this is not the case $(78.8 \%$ vs. $13.7 \%)$. This highlights the difficulties with making comparisons between studies due to study differences in not only the accelerometry thresholds for different intensities but also the exclusion of participants based on insufficient accelerometry wear time [12,13]. As we used a pooled dataset in which data has been processed in the same way across studies [26], the differences we have found between countries cannot be attributed to differences in data processing. We found that the greatest proportion of children reaching recommended TPA and MVPA guidelines were in the USA, followed by the UK, Switzerland, and Belgium. An exploratory subgroup analysis (data not shown), found the percentage of four-year-olds was highest in Switzerland followed by the UK, Belgium, and the USA, and the ratio of girls to boys was similar across the four countries. Most of the data were collected in autumn for UK, USA, and Switzerland-based children and in spring for Belgium-based children. Minutes of wear time were highest in the USA followed by Switzerland, Belgium, and the UK (see Supplementary Table S1). It is, therefore, unlikely that the between-country differences are a result of age, gender, season or minutes of wear time differences; which had been adjusted for in the regression analyses.

Visual inspection of the plots of ST by hour suggested that children spent fewer minutes in ST as the day progressed after an initial increase in ST levels until 09:00. In general, the figures showed that TPA and MVPA levels peaked either side of 11:00 and 15:00, with the peak observed after 15:00 being the highest level of PA reached in the day. Our findings are comparable to results from an Australian-based study [48] which found that ST was at its lowest and MVPA levels were at their highest from the mid-afternoon through to the evening on both weekdays and weekends. The dip in TPA and MVPA levels observed in the USA between 11:00 and 15:00 was greater in width and magnitude than the dips observed in Switzerland and the UK at around 12:00, which may represent differences in the childcare routines practiced by the different countries. The patterns of ST and PA in Belgium throughout the day were harder to distinguish, which is likely due to the lower sample size which contributed data. The dips in TPA and MVPA levels were more prominent on weekdays compared to weekends from 11:00 to 15:00 which may be representative of preschool lunchtime and napping procedures; however, we do not have preschool attendance data available to draw such conclusions. Reports from international early years settings suggest that compulsory sleep times are commonplace in childcare settings [49-51] which highlights the importance of having this information 
on policies and practices on sleep times available for analysis. The two peaks of MVPA levels in the morning and evening are elevated when the days are longer than $12 \mathrm{~h}$ long compared to being less than $12 \mathrm{~h}$ long. It could be suggested that more opportunities for outdoor play are available for children when the days are lighter, which is contributing to these higher activity levels [16].

Our findings from the regression analyses replicate those from other studies which found no association between age and ST [18-21,52-54] and found that girls were more sedentary than boys $[18,19,22,52]$. Children in Switzerland, Belgium, and the USA spent more minutes in ST than children in the UK. Our findings replicate results from another study which found that children were more sedentary in winter [22] compared to spring, whereas other studies only found that they were less sedentary in autumn [54] compared to spring or did not find an association between seasonality and ST [21,53]. We found no association between ST and ethnicity which is consistent with another study [19], and we found a positive association between ST and parental education which is not consistent with other studies $[18,19,22-24,53]$ that found no association with ST. It is possible that this is a chance finding due to the smaller sample sizes of participants who had ethnicity $(n=419)$ and parental education $(n=386)$ data. We found that children were more sedentary on weekdays compared to weekends, which is consistent with a previous study which found that hour-by-hour ST levels tended to be lower on weekends compared to weekdays [48].

It is well established that older preschoolers are more active than younger preschoolers $[18,21,22$, $25,54]$ and that boys are more active than girls $[18,21,22,25,39,53-57]$ although we did not observe a difference in minutes spent in TPA between three- and four-year-olds. We found that children in the UK were more physically active than children in Switzerland, Belgium, and the U.S.A, but there was less evidence to show that MVPA levels were higher in the USA. Similar to our findings, it has been observed elsewhere that children spend more time in MVPA in summer compared to winter [53] and another study observed that children were only more active in spring and not in summer compared to winter [39], although this was for MVPA not TPA as in our study. Another study found that children spent more time in TPA in summer compared to other seasons, [21] whereas others found that children spent more time in MVPA in summer and less time in winter compared to spring [22]. Previous studies found no associations with ethnicity [17] or parent education $[22,23,25,53,56,58]$ and PA measures, whereas we found that non-white children spent more time in MVPA than white children, and children whose parents had lower education levels spent greater time in TPA than those with higher parental education levels. We did not observe a difference between weekday and weekend data PA levels which is consistent with one study [59], whereas another study found that children spent more time in MVPA on weekends compared to weekdays [48]. When the hours of daylight were longer (including an earlier sunrise and later sunset) the children spent a greater time in PA and fewer minutes in ST which is comparable to a study looking at older children (5-16-years) which found that longer evening sunlight was associated with increased daily physical activity [60].

The strength of this study is that it adds to the limited literature on levels and correlates of objectively measured ST and PA in preschool-aged children. There have been a particularly limited number of studies which have previously examined ST and PA by ethnicity and parental education variables. Estimates for the ethnicity and parental education variables had large amounts of missingness. Therefore, we have assumed that these estimates would apply if the data were not missing. To our knowledge, there have been no previous literatures looking at differences in objectively measured ST/PA by country, time of sunrise, time of sunset, and hours of daylight in this age group. Consequently, there were no previous references to base our daylight variable categorizations on which may be a limitation in the analyses. As the data from the different studies within the ICAD have been processed in the same way, the results we present are a 'fair' comparison of levels of ST/PA across different countries which have not previously been possible. It is important to acknowledge that there are a relatively small number of children in each of the countries that were included in the sample. Therefore, our findings are not representative of each country's population. The studies included in the analysis sample are all based in high-income countries; therefore, our results may not be generalizable to 
low-to-middle-income countries. Data used in this study were collected between 1998 and 2009. Therefore, the results may not be generalizable to the current cohorts of preschool-aged children, especially given childrens' changing access to screens [61]. We were not provided with the raw data, so it was not possible to accurately identify the number of times children exceeded being sedentary for periods $\geq 60 \mathrm{~min}$ at a time; therefore, we were not able to measure the proportion of children meeting recommended ST guidelines. Based on the information provided in the ICAD [26] codebook, there is no information on napping, and as such, it appears that nap/sleep time may have been considered as non-wear time which may have led to the overestimation of ST levels and the underestimation of PA levels. The data is compositional in nature, therefore using compositional data techniques as opposed to standard techniques may have produced different results [62]. We did not have data available about childcare differences within and between samples, which could have been used to interpret our findings and to potentially explain between-country differences. Data from longitudinal studies can estimate modifiable factors associated with changes in ST and PA [63], whereas our cross-sectional study is limited in only providing evidence of associations.

\section{Conclusions}

Using data from four high-income countries, we found that children spent over eight hours per day in ST and $30.0 \%$ and $21.2 \%$ of children were not engaging in recommended daily amount of TPA ( $\geq 180 \mathrm{~min}$ ) and MVPA ( $\geq 60 \mathrm{~min}$ ), respectively. The minutes spent in ST decreased throughout the day and the dips in TPA and MVPA levels observed between 11:00 and 15:00 were greater in the USA compared to Switzerland, Belgium, and the UK and on weekdays compared to weekends. Age, gender, country, season, ethnicity, parental education, day of the week, time of sunrise, time of sunset, and hours of daylight were all identified as potential correlates of minutes spent in ST and/or TPA and/or MVPA. The associations between ethnicity and parental education with ST and PA were derived from smaller sample sizes and should be investigated further in a larger population. Internationally, there is a need for public health interventions, to decrease ST and increase PA levels in three-to-four-year-olds. The potential correlates identified in this study can be considered in designing these public health interventions. However, further research is needed to determine modifiable factors associated with ST and PA in preschool-aged children to inform effective behavior change programs.

Supplementary Materials: The following are available online at http://www.mdpi.com/1660-4601/16/11/1929/s1, Table S1: Average daily minutes spent in sedentary time, total physical activity, and moderate-to-vigorous physical activity by the different correlates, Table S2: Multi-level unadjusted associations between potential correlates and average daily minutes spent in sedentary time, total physical activity, and moderate-to-vigorous physical activity in children aged 3-to-4-years-old.

Author Contributions: Conceptualization, K.I.D., J.W., R.J. and R.K.; Formal analysis, K.I.D.; Investigation, K.I.D.; Methodology, K.I.D., J.W., R.J. and R.K.; Resources, G.C., R.D., K.F.J., R.R.P., J.J.P. and J.J.R.; Supervision, J.W., R.J. and R.K.; Visualization, K.I.D.; Writing—original draft, K.I.D.; Writing—review \& editing, K.I.D., J.W., R.J., G.C., R.D., K.F.J., R.R.P., J.J.P., J.J.R. and R.K.

Funding: This work was supported in part by grant MR/N0137941/1 for the GW4 BIOMED DTP, awarded to the Universities of Bath, Bristol, Cardiff, and Exeter from the Medical Research Council (MRC)/UKRI. The work was undertaken with the support of The Centre for the Development and Evaluation of Complex Interventions for Public Health Improvement (DECIPHer), a UKCRC Public Health Research Centre of Excellence. Joint funding (MR/KO232331/1) from the British Heart Foundation, Cancer Research UK, Economic and Social Research Council, Medical Research Council, the Welsh Government, and the Wellcome Trust, under the auspices of the UK Clinical Research Collaboration, is gratefully acknowledged. The pooling of the data was funded through a grant from the National Prevention Research Initiative (Grant Number: G0701877) (http://www.mrc.ac.uk/research/initiatives/national-prevention-research-initiative-npri/). The funding partners relevant to this award are: British Heart Foundation; Cancer Research UK; Department of Health; Diabetes UK; Economic and Social Research Council; Medical Research Council; Research and Development Office for the Northern Ireland Health and Social Services; Chief Scientist Office; Scottish Executive Health Department; The Stroke Association; Welsh Assembly Government, and World Cancer Research Fund. This work was additionally supported by the Medical Research Council [MC_UU_12015/3; MC_UU_12015/7], The Research Council of Norway (249932/F20), Bristol University, Loughborough University, and Norwegian School of Sport Sciences. 
Acknowledgments: The ICAD Collaborators include: Dr. Andrew J Atkin, Faculty of Medicine and Health Sciences, University of East Anglia, UK; Prof. Greet Cardon, Department of Movement and Sports Sciences, Ghent University, Belgium (Belgium Pre-School Study); Dr. Rachel Davey, Centre for Research and Action in Public Health, University of Canberra, Australia (Children's Health and Activity Monitoring for Schools (CHAMPS)); Prof. Ulf Ekelund, Norwegian School of Sport Sciences, Oslo, Norway and MRC Epidemiology Unit, University of Cambridge, UK; Dr. Dale W Esliger, School of Sports, Exercise and Health Sciences, Loughborough University, UK; Dr. Bjørge H Hansen, Norwegian School of Sport Sciences, Oslo, Norway; Prof. Kathleen F Janz, Department of Health and Human Physiology, Department of Epidemiology, University of Iowa, Iowa City, U.S. (Iowa Bone Development Study); Prof. Russell R Pate, Department of Exercise Science, University of South Carolina, Columbia, U.S. (Physical Activity in Pre-school Children (CHAMPS-US) and Project Trial of Activity for Adolescent Girls (Project TAAG)); Dr. Jardena J Puder, Service of Endocrinology, Diabetes and Metabolism, Centre Hospitalier Universitaire Vaudois, University of Lausanne, Switzerland (Ballabeina Study); Prof. John J Reilly, Physical Activity for Health Group, School of Psychological Sciences and Health, University of Strathclyde, Glasgow, UK (Movement and Activity Glasgow Intervention in Children (MAGIC)); Dr. Lauren B Sherar, School of Sports, Exercise and Health Sciences, Loughborough University, UK; Dr. Esther M F van Sluijs, MRC Epidemiology Unit and Centre for Diet and Activity Research, University of Cambridge, UK We would like to thank all participants and funders of the original studies that contributed data to ICAD. We gratefully acknowledge the past contributions of Prof. Chris Riddoch, Prof. Ken Judge, Prof Ashley Cooper and Dr. Pippa Griew to the development of ICAD. The ICAD was made possible thanks to the sharing of data from the following contributors: Prof. Lars B Andersen, Faculty of Teacher Education and Sport, Western Norway University of Applied Sciences, Sogndal, Norway (Copenhagen School Child Intervention Study (CoSCIS)); Prof. Sigmund Anderssen, Norwegian School for Sport Science, Oslo, Norway (European Youth Heart Study (EYHS), Norway); Prof. Greet Cardon, Department of Movement and Sports Sciences, Ghent University, Belgium (Belgium Pre-School Study); Centers for Disease Control and Prevention (CDC), National Center for Health Statistics (NCHS), Hyattsville, MD USA (National Health and Nutrition Examination Survey (NHANES)); Dr. Rachel Davey, Centre for Research and Action in Public Health, University of Canberra, Australia (Children's Health and Activity Monitoring for Schools (CHAMPS)); Dr. Pedro Hallal, Postgraduate Program in Epidemiology, Federal University of Pelotas, Brazil (1993 Pelotas Birth Cohort); Prof. Kathleen F Janz, Department of Health and Human Physiology, Department of Epidemiology, University of Iowa, Iowa City, U.S. (Iowa Bone Development Study); Prof. Susi Kriemler, Epidemiology, Biostatistics and Prevention Institute, University of Zürich, Switzerland (Kinder-Sportstudie (KISS)); Dr. Niels C Møller, University of Southern Denmark, Odense, Denmark (European Youth Heart Study (EYHS), Denmark); Dr. Kate Northstone, School of Social and Community Medicine, University of Bristol, UK (Avon Longitudinal Study of Parents and Children (ALSPAC)); Dr. Angie S Page, Centre for Exercise, Nutrition and Health Sciences, University of Bristol, UK (Personal and Environmental Associations with Children's Health (PEACH)); Prof. Russell R Pate, Department of Exercise Science, University of South Carolina, Columbia, U.S. (Physical Activity in Pre-school Children (CHAMPS-US) and Project Trial of Activity for Adolescent Girls (Project TAAG)); Dr. Jardena J Puder, Service of Endocrinology, Diabetes and Metabolism, Centre Hospitalier Universitaire Vaudois, University of Lausanne, Switzerland (Ballabeina Study); Prof. John J. Reilly, Physical Activity for Health Group, School of Psychological Sciences and Health, University of Strathclyde, Glasgow, UK (Movement and Activity Glasgow Intervention in Children (MAGIC)); Prof. Jo Salmon, Institute for Physical Activity and Nutrition (IPAN), School of Exercise and Nutrition Sciences, Deakin University, Geelong, Australia (Children Living in Active Neigbourhoods (CLAN) and Healthy Eating and Play Study (HEAPS)); Prof. Luis B Sardinha, Exercise and Health Laboratory, Faculty of Human Movement, Universidade de Lisboa, Lisbon, Portugal (European Youth Heart Study (EYHS), Portugal); Dr. Esther M F van Sluijs, MRC Epidemiology Unit and Centre for Diet and Activity Research, University of Cambridge, UK (Sport, Physical activity and Eating behaviour: Environmental Determinants in Young people (SPEEDY)).

Conflicts of Interest: The authors declare no conflict of interest.

\section{References}

1. Malina, R.M. Physical activity and fitness: pathways from childhood to adulthood. Am. J. Hum. Biol. 2001, 13, 162-172. [CrossRef]

2. Timmons, B.W.; Leblanc, A.G.; Carson, V.; Connor Gorber, S.; Dillman, C.; Janssen, I.; Kho, M.E.; Spence, J.C.; Stearns, J.A.; Tremblay, M.S. Systematic review of physical activity and health in the early years (aged 0-4 years). Appl. Physiol. Nutr. Metab. 2012, 37,773-792. [CrossRef]

3. Tremblay, M.S.; Chaput, J.P.; Adamo, K.B.; Aubert, S.; Barnes, J.D.; Choquette, L.; Duggan, M.; Faulkner, G.; Goldfield, G.S.; Gray, C.E.; et al. Canadian 24-Hour Movement Guidelines for the Early Years (0-4 years): An Integration of Physical Activity, Sedentary Behaviour, and Sleep. BMC Public Health 2017, 17, 874. [CrossRef]

4. Australian Government. Get up and Grow: Healthy Eating and Physical Activity for Early Childhood; Department of Health and Aging: Adelaide, Australia, 2010.

5. Piercy, K.L.; Troiano, R.P.; Ballard, R.M.; Carlson, S.A.; Fulton, J.E.; Galuska, D.A.; George, S.M.; Olson, R.D. The Physical Activity Guidelines for Americans. JAMA 2018, 320, 2020-2028. [CrossRef] 
6. Chief Medical Officers. Start Active, Stay Active: A Report on Physical Activity for Health from the Four Home Countries' Chief Medical Officers; Department of Health and Social Care: London, UK, 2011.

7. Hesketh, K.R.; Griffin, S.J.; van Sluijs, E.M. UK Preschool-aged children's physical activity levels in childcare and at home: A cross-sectional exploration. Int. J. Behav. Nutr. Phys. Act. 2015, 12, 123. [CrossRef] [PubMed]

8. Hesketh, K.R.; McMinn, A.M.; Ekelund, U.; Sharp, S.J.; Collings, P.J.; Harvey, N.C.; Godfrey, K.M.; Inskip, H.M.; Cooper, C.; van Sluijs, E.M. Objectively measured physical activity in four-year-old British children: A cross-sectional analysis of activity patterns segmented across the day. Int. J. Behav. Nutr. Phys. Act. 2014, 11, 1. [CrossRef] [PubMed]

9. De Craemer, M.; McGregor, D.; Androutsos, O.; Manios, Y.; Cardon, G. Compliance with 24-h Movement Behaviour Guidelines among Belgian Pre-School Children: The ToyBox-Study. Int. J. Environ. Res. Public Health 2018, 15, 2171. [CrossRef] [PubMed]

10. Hinkley, T.; Salmon, J.; Okely, A.D.; Crawford, D.; Hesketh, K. Preschoolers' physical activity, screen time, and compliance with recommendations. Med. Sci. Sports Exerc. 2012, 44, 458-465. [CrossRef] [PubMed]

11. Colley, R.C.; Garriguet, D.; Adamo, K.B.; Carson, V.; Janssen, I.; Timmons, B.W.; Tremblay, M.S. Physical activity and sedentary behavior during the early years in Canada: A cross-sectional study. Int. J. Behav. Nutr. Phys. Act. 2013, 10, 54. [CrossRef]

12. Cliff, D.P.; Reilly, J.J.; Okely, A.D. Methodological considerations in using accelerometers to assess habitual physical activity in children aged 0-5 years. J. Sci. Med. Sport 2009, 12, 557-567. [CrossRef] [PubMed]

13. Oliver, M.; Schofield, G.M.; Kolt, G.S. Physical activity in preschoolers: Understanding prevalence and measurement issues. Sports Med. 2007, 37, 1045-1070. [CrossRef]

14. Baranowski, T.; Jago, R. Understanding the mechanisms of change in children's physical activity programs. Exerc. Sport Sci. Rev. 2005, 33, 163-168. [CrossRef] [PubMed]

15. Hinkley, T.; Salmon, J.; Okely, A.D.; Trost, S.G. Correlates of sedentary behaviours in preschool children: A review. Int. J. Behav. Nutr. Phys. Act. 2010, 7, 66. [CrossRef] [PubMed]

16. De Craemer, M.; De Decker, E.; De Bourdeaudhuij, I.; Vereecken, C.; Deforche, B.; Manios, Y.; Cardon, G.; ToyBox-Study Group. Correlates of energy balance-related behaviours in preschool children: A systematic review. Obes Rev 2012, 13 (Suppl. 1), 13-28. [CrossRef]

17. Hinkley, T.; Crawford, D.; Salmon, J.; Okely, A.D.; Hesketh, K. Preschool children and physical activity: A review of correlates. Am. J. Prev. Med. 2008, 34, 435-441. [CrossRef] [PubMed]

18. Dolinsky, D.H.; Brouwer, R.J.; Evenson, K.R.; Siega-Riz, A.M.; Ostbye, T. Correlates of sedentary time and physical activity among preschool-aged children. Prev. Chronic Dis. 2011, 8, A131. [PubMed]

19. Byun, W.; Dowda, M.; Pate, R.R. Correlates of objectively measured sedentary behavior in US preschool children. Pediatrics 2011, 128, 937-945. [CrossRef]

20. Hnatiuk, J.A.; Hesketh, K.R.; van Sluijs, E.M. Correlates of home and neighbourhood-based physical activity in UK 3-4-year-old children. Eur. J. Public Health 2016, 26, 947-953. [CrossRef]

21. Schmutz, E.A.; Leeger-Aschmann, C.S.; Radtke, T.; Muff, S.; Kakebeeke, T.H.; Zysset, A.E.; Messerli-Burgy, N.; Stulb, K.; Arhab, A.; Meyer, A.H.; et al. Correlates of preschool children's objectively measured physical activity and sedentary behavior: A cross-sectional analysis of the SPLASHY study. Int. J. Behav. Nutr. Phys. Act. 2017, 14, 1. [CrossRef]

22. Wijtzes, A.I.; Kooijman, M.N.; Kiefte-de Jong, J.C.; de Vries, S.I.; Henrichs, J.; Jansen, W.; Jaddoe, V.W.; Hofman, A.; Moll, H.A.; Raat, H. Correlates of physical activity in 2-year-old toddlers: The generation $\mathrm{R}$ study. J. Pediatr. 2013, 163, 791-799. [CrossRef]

23. Johansson, E.; Hagstromer, M.; Svensson, V.; Ek, A.; Forssen, M.; Nero, H.; Marcus, C. Objectively measured physical activity in two-year-old children-Levels, patterns and correlates. Int. J. Behav. Nutr. Phys. Act. 2015, 12, 3. [CrossRef]

24. Downing, K.L.; Hinkley, T.; Salmon, J.; Hnatiuk, J.A.; Hesketh, K.D. Do the correlates of screen time and sedentary time differ in preschool children? BMC Public Health. 2017, 17, 285.

25. Hager, E.R.; Gormley, C.E.; Latta, L.W.; Treuth, M.S.; Caulfield, L.E.; Black, M.M. Toddler physical activity study: Laboratory and community studies to evaluate accelerometer validity and correlates. BMC Public Health 2016, 16, 936. [CrossRef]

26. Sherar, L.B.; Griew, P.; Esliger, D.W.; Cooper, A.R.; Ekelund, U.; Judge, K.; Riddoch, C. International children's accelerometry database (ICAD): Design and methods. BMC Public Health 2011, 11, 485. [CrossRef] 
27. Hinkley, T.; O'Connell, E.; Okely, A.D.; Crawford, D.; Hesketh, K.; Salmon, J. Assessing volume of accelerometry data for reliability in preschool children. Med. Sci. Sports Exerc. 2012, 44, 2436-2441. [CrossRef]

28. Niederer, I.; Kriemler, S.; Zahner, L.; Burgi, F.; Ebenegger, V.; Hartmann, T.; Meyer, U.; Schindler, C.; Nydegger, A.; Marques-Vidal, P.; et al. Influence of a lifestyle intervention in preschool children on physiological and psychological parameters (Ballabeina): Study design of a cluster randomized controlled trial. BMC Public Health 2009, 9, 94. [CrossRef]

29. Cardon, G.; Labarque, V.; Smits, D.; De Bourdeaudhuij, I. Promoting physical activity at the pre-school playground: The effects of providing markings and play equipment. Prev. Med. 2009, 48, 335-340. [CrossRef]

30. Cardon, G.; De Bourdeaudhuij, I. Comparison of pedometer and accelerometer measures of physical activity in preschool children. Pediatr. Exerc. Sci. 2007, 19, 205-214. [CrossRef]

31. Van Cauwenberghe, E.; Labarque, V.; Trost, S.G.; de Bourdeaudhuij, I.; Cardon, G. Calibration and comparison of accelerometer cut points in preschool children. Int. J. Pediatr. Obes. 2010, 6, e582-e589. [CrossRef]

32. Gidlow, C.J.; Cochrane, T.; Davey, R.; Smith, H. In-school and out-of-school physical activity in primary and secondary school children. J. Sports Sci. 2008, 26, 1411-1419. [CrossRef]

33. Smith, H.; Grogan, S.; Davey, R.; Cochrane, T. Developing a successful physical activity intervention in primary schools. Educ. Health 2009, 27, 63-66.

34. Pfeiffer, K.A.; Dowda, M.; McIver, K.L.; Pate, R.R. Factors related to objectively measured physical activity in preschool children. Pediatr. Exerc. Sci. 2009, 21, 196-208. [CrossRef] [PubMed]

35. Janz, K.F.; Burns, T.L.; Torner, J.C.; Levy, S.M.; Paulos, R.; Willing, M.C.; Warren, J.J. Physical activity and bone measures in young children: The Iowa bone development study. Pediatrics 2001, 107, 1387-1393. [CrossRef] [PubMed]

36. Janz, K.F.; Gilmore, J.M.; Burns, T.L.; Levy, S.M.; Torner, J.C.; Willing, M.C.; Marshall, T.A. Physical activity augments bone mineral accrual in young children: The Iowa Bone Development study. J. Pediatr. 2006, 148, 793-799. [CrossRef] [PubMed]

37. Reilly, J.J.; Kelly, L.; Montgomery, C.; Williamson, A.; Fisher, A.; McColl, J.H.; Lo Conte, R.; Paton, J.Y.; Grant, S. Physical activity to prevent obesity in young children: Cluster randomised controlled trial. BMJ 2006, 333, 1041. [CrossRef]

38. Troiano, R.P.; Berrigan, D.; Dodd, K.W.; Masse, L.C.; Tilert, T.; McDowell, M. Physical activity in the United States measured by accelerometer. Med. Sci. Sports Exerc. 2008, 40, 181-188. [CrossRef] [PubMed]

39. Van Sluijs, E.M.; McMinn, A.M.; Inskip, H.M.; Ekelund, U.; Godfrey, K.M.; Harvey, N.C.; Griffin, S.J. Correlates of light and moderate-to-vigorous objectively measured physical activity in four-year-old children. PLOS ONE 2013, 8, e74934. [CrossRef]

40. Puyau, M.R.; Adolph, A.L.; Vohra, F.A.; Butte, N.F. Validation and calibration of physical activity monitors in children. Obes. Res. 2002, 10, 150-157. [CrossRef] [PubMed]

41. Pate, R.R.; Almeida, M.J.; McIver, K.L.; Pfeiffer, K.A.; Dowda, M. Validation and calibration of an accelerometer in preschool children. Obesity 2006, 14, 2000-2006. [CrossRef]

42. Snijders, T.; Bosker, R. Multilevel Analysis: An Introduction to Basic and Advanced Multilevel Modeling; SAGE Publications Ltd.: London, UK, 1999.

43. Byun, W.; Beets, M.W.; Pate, R.R. Sedentary Behavior in Preschoolers: How Many Days of Accelerometer Monitoring Is Needed? Int. J. Environ. Res. Public Health 2015, 12, 13148-13161. [CrossRef]

44. Addy, C.L.; Trilk, J.L.; Dowda, M.; Byun, W.; Pate, R.R. Assessing preschool children's physical activity: How many days of accelerometry measurement. Pediatr. Exerc. Sci. 2014, 26, 103-109. [CrossRef]

45. Wong, S.L.; Colley, R.; Connor Gorber, S.; Tremblay, M. Actical accelerometer sedentary activity thresholds for adults. J. Phys. Act. Health 2011, 8, 587-591. [CrossRef]

46. Reilly, J.J.; Coyle, J.; Kelly, L.; Burke, G.; Grant, S.; Paton, J.Y. An objective method for measurement of sedentary behavior in 3- to 4-year olds. Obes. Res. 2003, 11, 1155-1158. [CrossRef]

47. Sirard, J.R.; Trost, S.G.; Pfeiffer, K.A.; Dowda, M.; Pate, R.R. Calibration and Evaluation of an Objective Measure of Physical Activity in Preschool Children. J. Phys. Act. Health 2005, 3, 345-357. [CrossRef]

48. Van Cauwenberghe, E.; Jones, R.A.; Hinkley, T.; Crawford, D.; Okely, A.D. Patterns of physical activity and sedentary behaviour in preschool children. Int. J. Behav. Nutr. Phys. Act. 2012, 9, 138. [CrossRef] [PubMed]

49. Fukuda, K.; Sakashita, Y. Sleeping pattern of kindergartners and nursery school children: Function of daytime nap. Percept. Mot Skills 2002, 94, 219-228. [CrossRef] 
50. Pattinson, C.L.; Staton, S.L.; Smith, S.S.; Sinclair, D.M.; Thorpe, K.J. Emotional Climate and Behavioral Management during Sleep Time in Early Childhood Education Settings. Early Child. Res. Q. 2014, 29, 660-668. [CrossRef]

51. Ward, T.M.; Gay, C.; Anders, T.F.; Alkon, A.; Lee, K.A. Sleep and napping patterns in 3-to-5-year old children attending full-day childcare centers. J. Pediatr. Psychol. 2008, 33, 666-672. [CrossRef]

52. Byun, W.; Blair, S.N.; Pate, R.R. Objectively measured sedentary behavior in preschool children: Comparison between Montessori and traditional preschools. Int. J. Behav. Nutr. Phys. Act. 2013, 10, 2. [CrossRef]

53. Bringolf-Isler, B.; Mader, U.; Dossegger, A.; Hofmann, H.; Puder, J.J.; Braun-Fahrlander, C.; Kriemler, S. Regional differences of physical activity and sedentary behaviour in Swiss children are not explained by socio-demographics or the built environment. Int. J. Public Health 2015, 60, 291-300. [CrossRef]

54. Leeger-Aschmann, C.S.; Schmutz, E.A.; Radtke, T.; Kakebeeke, T.H.; Zysset, A.E.; Messerli-Burgy, N.; Stulb, K.; Arhab, A.; Meyer, A.H.; Munsch, S.; et al. Regional sociocultural differences as important correlate of physical activity and sedentary behaviour in Swiss preschool children. Swiss Med. Wkly. 2016, 146, w14377. [CrossRef]

55. Dowda, M.; Pfeiffer, K.A.; Brown, W.H.; Mitchell, J.A.; Byun, W.; Pate, R.R. Parental and environmental correlates of physical activity of children attending preschool. Arch. Pediatr. Adolesc. Med. 2011, 165, 939-944. [CrossRef] [PubMed]

56. Olesen, L.G.; Kristensen, P.L.; Korsholm, L.; Froberg, K. Physical activity in children attending preschools. Pediatrics 2013, 132, e1310-e1318. [CrossRef] [PubMed]

57. Eichinger, M.; Schneider, S.; De Bock, F. Subjectively and objectively assessed social and physical environmental correlates of preschoolers' accelerometer-based physical activity. Int. J. Behav. Nutr. Phys. Act. 2017, 14, 153. [CrossRef] [PubMed]

58. Hinkley, T.; Salmon, J.; Okely, A.D.; Hesketh, K.; Crawford, D. Correlates of preschool children's physical activity. Am. J. Prev. Med. 2012, 43, 159-167. [CrossRef] [PubMed]

59. Cardon, G.M.; De Bourdeaudhuij, I.M. Are preschool children active enough? Objectively measured physical activity levels. Res. Q. Exerc. Sport 2008, 79, 326-332. [CrossRef] [PubMed]

60. Goodman, A.; Page, A.S.; Cooper, A.R.; International Children's Accelerometry Database (ICAD) Collaborators. Daylight saving time as a potential public health intervention: An observational study of evening daylight and objectively-measured physical activity among 23,000 children from 9 countries. Int. J. Behav. Nutr. Phys. Act. 2014, 11, 84. [CrossRef]

61. Mullan, K. Technology and Children's Screen-Based Activities in the UK: The Story of the Millennium So Far. Child Indic. Res. 2018, 11, 1781-1800. [CrossRef]

62. Gupta, N.; Mathiassen, S.E.; Mateu-Figueras, G.; Heiden, M.; Hallman, D.M.; Jorgensen, M.B.; Holtermann, A. A comparison of standard and compositional data analysis in studies addressing group differences in sedentary behavior and physical activity. Int. J. Behav. Nutr. Phys. Act. 2018, 15, 53. [CrossRef]

63. Hesketh, K.R.; O'Malley, C.; Paes, V.M.; Moore, H.; Summerbell, C.; Ong, K.K.; Lakshman, R.; van Sluijs, E.M.F. Determinants of Change in Physical Activity in Children 0-6 years of Age: A Systematic Review of Quantitative Literature. Sports Med. 2017, 47, 1349-1374. [CrossRef]

(C) 2019 by the authors. Licensee MDPI, Basel, Switzerland. This article is an open access article distributed under the terms and conditions of the Creative Commons Attribution (CC BY) license (http://creativecommons.org/licenses/by/4.0/). 